\title{
Child Neurology: A young child with an undiagnosed case of dystonia responsive to L-dopa
}

Steven P. Trau, MD, William B. Gallentine, DO, and Mohamad A. Mikati, MD

Neurology ${ }^{\circledR}$ 2020;94:326-328. doi:10.1212/WNL.0000000000008963
Correspondence

Dr. Mikati

mohamad.mikati@duke.edu

\begin{abstract}
Childhood-onset dystonias are a heterogeneously diverse group. There exists a specific set of dystonias that respond profoundly well to low doses of $\mathrm{L}$-dopa (dopa-responsive dystonia [DRD]). Classical DRD is caused by deficiency of GTP cyclohydrolase 1 or tyrosine hydroxylase, but other conditions can cause dystonias that are partially responsive to dopamine. The idea of a diagnostic therapeutic trial with L-dopa for children who present with dystonia has been around for decades and is frequently advocated for; however, L-dopa trials are not without risk.

We present a child with an L-dopa-responsive dystonia with a negative causative workup including whole exome sequencing (WES) whose treatment with L-dopa would likely have been delayed or not attempted without a diagnostic therapeutic trial of L-dopa early in his disease course. To our knowledge, this is the first case of a gene-negative dopa-responsive dystonia (DRD).
\end{abstract}

\section{Case report}

A 26-month-old boy with a history of a single simple febrile seizure at age 1 year presented to the emergency department (ED) with episodes of inability to bear weight associated with his legs "locking up," lasting for a few minutes at a time. He had similar episodes the prior year that occurred intermittently for several weeks before self-resolving. Workup for the episodes at that time included a negative routine EEG. He was noted to be febrile on arrival to the ED. A stroke code was activated; rapid MRI was negative for stroke. Lumbar puncture was performed and was unremarkable; CSF neurotransmitters were not sent. Complete blood count and urinalysis were also normal. He was noted to have episodes of bilateral lower extremity stiffening lasting for several minutes at a time, so he was admitted for episode characterization.

EEG was performed, which captured several episodes of lower extremity extension and posturing, which were all nonepileptic and clinically consistent with dystonia. Due to clinical concern for dystonic posturing, the patient was started empirically on carbidopa-levodopa 1.9 $\mathrm{mg} / \mathrm{kg} / \mathrm{d}$ (once daily dosing), which resolved his episodes. He was discharged with plan for outpatient MRI.

An MRI of the brain without contrast (figure) showed periventricular white matter changes concerning for delayed myelination vs dysmyelination. Following discharge, the patient continued to do well, with only a single episode of leg dystonia in the next 3 weeks. An empiric trial of stopping carbidopa-levodopa resulted in return of his dystonic leg posturing several times per week (worse following exercise and at night) as well as new-onset stuttering, all of which again resolved following resumption of carbidopa-levodopa. 


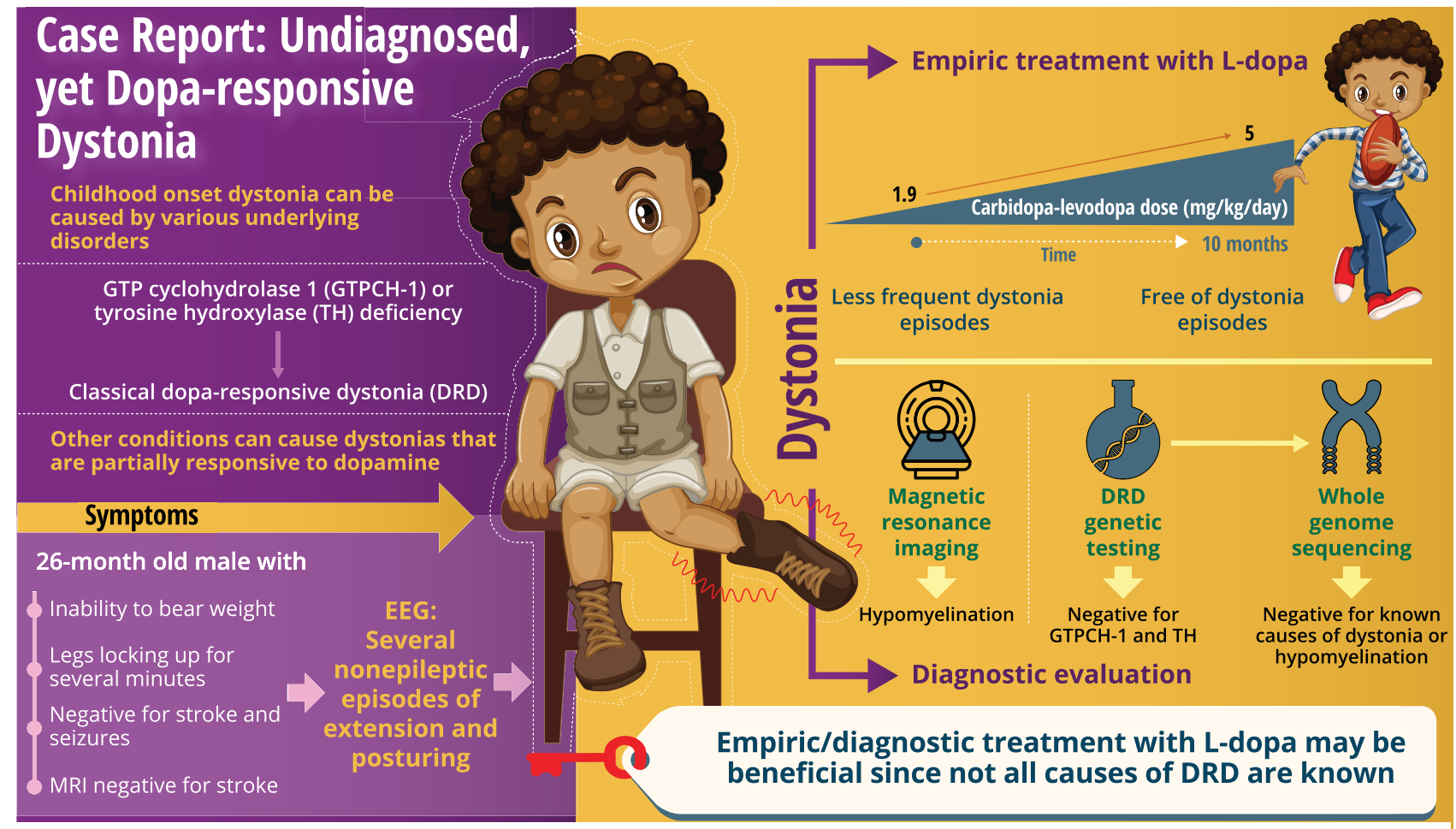

doi:10.1212/WNL.0000000000008963

Copyright $\odot 2019$ American Academy of Neurology

Neurology

Genetic testing for classic DRD (GCH1 and TH) was negative. Repeat MRI 6 months later was unchanged, suggesting dysmyelination. Trio WES (GeneDx) was sent and returned negative for causative mutations (whole exome mean depth of coverage of $108 \times$ with minimum depth of coverage of $10 \times$ covered for $98.7 \%$ of the exome).

At the time of his most recent evaluation (36 months old), the patient remained free of dystonic episodes on carbidopa-levodopa, although his dosage was increased over time to $5 \mathrm{mg} / \mathrm{kg} / \mathrm{d}$ (once daily dosing). Interestingly, his mother reported that she began to have similar episodes of painful nighttime foot and leg stiffening lasting for several minutes while his evaluation was

Figure T2-weighted axial image at age 26 months shows increased T2 signal in white matter, particularly posteriorly and on the right

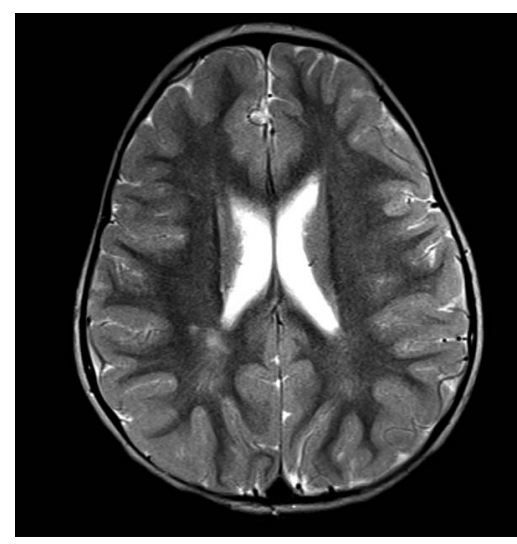

ongoing; she has not yet established care with a neurologist. Throughout his course, the patient has continued to meet all developmental milestones on time but has developed new-onset sound sensitivity and mild obsessive-compulsive behaviors.

\section{Discussion}

Levodopa was first used empirically for a hereditary childhood-onset dystonia with diurnal variation in $1971 .{ }^{1}$ The patients were eventually shown to have deficiency of GTP cyclohydrolase 1 (GTP-CH-I), which is encoded by GCH1. ${ }^{2}$ Monoamine neurotransmitter production depends on GTP$\mathrm{CH}-\mathrm{I}$ to occur as it is an essential cofactor. Deficiencies in other enzymes involved in the synthesis of dopamine have also been shown to respond to treatment with L-dopa, including tyrosine hydroxylase (TH), 6-pyruvoyl tetrahydrobiopterin synthase (PTPS), and sepiapterin reductase (SR). In addition to deficiencies in enzymes responsible for dopamine biosynthesis, other conditions, including spinocerebellar ataxia type 3 (SCA3), ataxia telangiectasia, hereditary spastic paraplegia type 11 , parkin deletions, lesions of the substantia nigra, paroxysmal nonkinesigenic dyskinesia, and others, have been shown to involve dystonia that may respond incompletely to treatment with Ldopa. Further conditions that may partially respond to dopamine include glucose transporter type 1 deficiency, dihydropteridine reductase deficiency, aromatic L-amino acid decarboxylase deficiency, dopamine transporter deficiency, vesicular monoamine transporter 2 deficiency, SOX6 mutation, juvenile Parkinson disease, pallidopyramidal syndrome, and DYT1 mutation.,

The idea of a diagnostic therapeutic trial with L-dopa has been traced back to Nygaard et $\mathrm{al}^{5}$ but more recently questioned by 
Maas et al. ${ }^{4}$ Over time, the debate on whether "every child with dystonia deserves a trial with L-dopa" has gone on. Some recent reviews argue for an empiric trial of levodopa. ${ }^{3,6}$ Others argue against an empiric trial until a definitive diagnosis of DRD has been made for multiple reasons including the risk of side effects with L-dopa and the relative ease of diagnosis. ${ }^{4}$ Side effects from treatment with levodopa are possible and include headache, nausea, paresthesias, confusion, and dyskinesias; Lumsden et al. ${ }^{7}$ recently reported that $26 / 57$ children treated with levodopa for dystonia eventually discontinued use due to side effects. In addition, the range of dosages required for successful treatment has wide variability, from 0.5 up to $20 \mathrm{mg} / \mathrm{kg} / \mathrm{d}$ (although most children respond to $4-5 \mathrm{mg} / \mathrm{kg} / \mathrm{d}){ }^{4,8}$ Maas et al. ${ }^{4}$ further qualified their argument that patients with classical DRD could be given a therapeutic trial of L-dopa with concurrent further investigation with genetic testing. It could alternatively be argued, however, that even some cases of classical DRD do not present with diurnal variation. Furthermore, some patients with classical DRD respond rapidly to low-dose L-dopa, so a brief trial at low dose may be a reasonable first step in all young patients with dystonia in order to guide the next steps of evaluation.

Our patient did not present with classical DRD given the lack of diurnal fluctuation. However, we performed an empiric trial of L-dopa (rather than CSF neurotransmitter analysis) because it was not considered necessary to perform a procedure that would require sedation when the option for an alternative was available. Should the trial at low dose have been negative, we had the intention to reevaluate the need for further workup. Given the dramatic response to low-dose and once daily L-dopa administration, this was not needed.

Subsequent workup revealed white matter changes on MRI suggestive of delayed myelination vs dysmyelination. Given the otherwise benign course, delayed myelination was favored; however, repeat MRI 6 months later was unchanged, which suggested a dysmyelinating process. None of the classically cited DRDs (GCH1 deficiency and TH deficiency, in addition to less common conditions responding to L-dopa such as SR deficiency, PTPS deficiency, and SCA3) are associated with abnormal white matter. Therefore, adding in potential leukodystrophy/hypomyelination diseases on top of the already known L-dopa-responsive dystonia drastically increased the potential diagnoses. WES was performed, which was negative for any pathogenic variant or variant of unknown significance for any known causes of dystonia or myelination disorder. Interestingly, our patient's mother developed similar symptoms of dystonia with diurnal variation during the evaluation process, pointing towards a presumed genetic cause even with the negative WES.

At this point, a lumbar puncture for CSF neurotransmitters will not be performed, since exogenous administration of $\mathrm{L}$-dopa may interfere with interpretation, and we do not believe that even temporarily discontinuing treatment for a diagnostic evaluation would be in the patient's best interest. WES has several limitations, including inability to detect copy number variants, analyze epigenetic factors, look for uniparental disomy, and analyze for nucleotide repeats, and not all exons can be tested completely. In addition, promoter regions, introns, and other noncoding regions are not analyzed in WES but could still contribute to disease processes. The patient will be referred for whole genome sequencing as the next step in his evaluation.

Proposed diagnostic strategies for dystonia that can reveal classic DRD include genetic testing for $G C H 1$ and $T H$; further testing for less common causes of DRDs (SR and PTPS deficiency); SPECT imaging; lumbar puncture for neurotransmitter metabolites, neopterin, and tetrahydrobiopterin; and next generation sequencing/WES. However, the heterogeneity of other known conditions that can (more rarely) respond to treatment with L-dopa makes testing for every possible genetic cause of a potential L-dopa-responsive dystonia more difficult. Waiting for a firm diagnosis of our patient's dystonia would therefore have prevented or drastically delayed treatment with L-dopa, which was conclusively shown early in his course to completely correct his dystonic episodes.

\section{Author contributions}

S.P. Trau: drafting/revising the manuscript, accepts responsibility for conduct of research and final approval. W.B. Gallentine: drafting/revising the manuscript, analysis or interpretation of data, accepts responsibility for conduct of research and final approval. M.A. Mikati: drafting/revising the manuscript, study concept or design, analysis or interpretation of data, accepts responsibility for conduct of research and final approval, acquisition of data, study supervision.

\section{Study funding}

No targeted funding reported.

\section{Disclosure}

The authors report no disclosures relevant to the manuscript. Go to Neurology.org/N for full disclosures.

\section{References}

1. Segawa M, Hosaka A, Miyagawa F, Nomura Y, Imai H. Hereditary progressive dystonia with marked diurnal fluctuation. Adv Neurol 1976;14:215-233.

2. Ichinose $\mathrm{H}$, Ohye $\mathrm{T}$, Takahashi E, et al. Hereditary progressive dystonia with marked diurnal fluctuation caused by mutations in the GTP cyclohydrolase I gene. Nat Genet $1994 ; 8: 236-242$.

3. Wijemanne S, Jankovic J. Dopa-responsive dystonia: clinical and genetic heterogeneity. Nat Rev Neurol 2015;11:414.

4. Maas RPPWM, Wassenberg T, Lin JP, van de Warrenburg BPC, Willemsen MAAP. L-Dopa in dystonia: a modern perspective. Neurology 2017;88: 1865-1871.

5. Nygaard TG, Marsden CD, Duvoisin RC. Dopa-responsive dystonia. Adv Neurol 1988;50:377-384.

6. Koy A, Lin JP, Sanger TD, Marks WA, Mink JW, Timmermann L. Advances in management of movement disorders in children. Lancet Neurol 2016;15: 719-735.

7. Lumsden DE, Kaminska M, Tomlin S, Lin JP. Medication use in childhood dystonia. Eur J Paediatr Neurol 2016;20:625-629.

8. Cloud L, Jinnah H. Treatment strategies for dystonia. Expert Opin Pharmacother 2010;11:5-15. 


\section{Neurology}

\section{Child Neurology: A young child with an undiagnosed case of dystonia responsive to l-dopa \\ Steven P. Trau, William B. Gallentine and Mohamad A. Mikati}

Neurology 2020;94;326-328 Published Online before print February 3, 2020

DOI 10.1212/WNL.0000000000008963

This information is current as of February 3, 2020

\section{Updated Information \&} Services

References

Subspecialty Collections

Permissions \& Licensing

Reprints including high resolution figures, can be found at: http://n.neurology.org/content/94/7/326.full

This article cites 8 articles, 1 of which you can access for free at: http://n.neurology.org/content/94/7/326.full\#ref-list-1

This article, along with others on similar topics, appears in the following collection(s):

All Genetics

http://n.neurology.org/cgi/collection/all_genetics

All Movement Disorders

http://n.neurology.org/cgi/collection/all_movement_disorders

All Pediatric

http://n.neurology.org/cgi/collection/all_pediatric

Leukodystrophies

http://n.neurology.org/cgi/collection/leukodystrophies

Information about reproducing this article in parts (figures,tables) or in its entirety can be found online at:

http://www.neurology.org/about/about_the_journal\#permissions

Information about ordering reprints can be found online:

http://n.neurology.org/subscribers/advertise

Neurology ${ }^{\circledR}$ is the official journal of the American Academy of Neurology. Published continuously since 1951, it is now a weekly with 48 issues per year. Copyright @ 2020 American Academy of Neurology. All rights reserved. Print ISSN: 0028-3878. Online ISSN: 1526-632X.

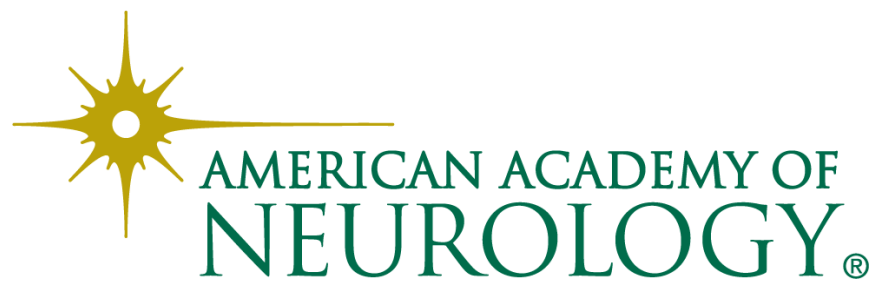

